\title{
THE THERMOPHYSICAL PROPERTIES OF THREE GLOBULAR MOLECULES
}

\author{
E. F. WESTRUM, Jr. \\ Department of Chemistry, University of Michigan, Ann Arbor, Michigan
}

\begin{abstract}
The low temperature heat capacities of adamantane, hexamethylenetetramine and triethylenediamine have been determined from 5 to $350^{\circ} \mathrm{K}$ by adiabatic calorimetry. A transition at $208.6^{\circ} \mathrm{K}$ involving an entropy increment of 3.87 e.u. is associated with a slight modification of the crystalline arrangement and the molecular freedom in adamantane. Although a related transition also occurs in triethylenediamine at $353^{\circ} \mathrm{K}$, none has yet been detected in hexamethylenetetramine.
\end{abstract}

\section{ADAMANTANE AND HEXAMETHYLENE- TETRAMINE}

OF THE many molecules which may be classified as "globular"(1) few approach geometrical or force field sphericity to the extent of adamantane,* which is the simplest saturated polycyclic hydrocarbon possessing a cage-like skeleton like that of the crystalline lattice of diamond. This interesting substance exists in a face-centered cubic array with a $T_{d}^{2}-F 43 m$ space group at room temperature according to NowACKI ${ }^{(2)}$ (although it is presently considered that this phase represents a disordered structure), melts at $270^{\circ} \mathrm{C}$, (3) and moreover undergoes an apparently first order transition ${ }^{(4)}$ to a body-centered tetragonal lattice at $208.62^{\circ} \mathrm{K}$ with the tentative unit cell dimension $a=6.641 \AA$ and $c=8.875 \AA .^{(5)}$ A schematic diagram of its molecular structure is presented in Fig. 1(a). The compound was synthesized by the method of SCHLEYER ${ }^{(6)}$ and its purity established by chemical X-ray diffraction and gas chromatography.

A closely related substance, hexamethylenetetramine, $\uparrow[\mathrm{cf}$. Fig. 1(b)], which may be considered to be "derived" from adamantane by replacement of the four methine (CH) groups with nitrogen atoms, on the other hand apparently does not undergo transition to a plastic crystalline phase

\footnotetext{
* $\mathrm{C}_{10} \mathrm{H}_{16}$, tricyclo[3,3,1,18,7]decane.

$+\mathrm{C}_{0} \mathrm{~N}_{4} \mathrm{H}_{12}, 1,3,5,7$-tetrazatricyclo[3,3,1,13.7] decane.
}

below $240^{\circ} \mathrm{C}$ and possibly not before decomposition or fusion. Its structure is that of a bodycentered cubic lattice of space group $T_{a}^{3}-I \overline{43} \mathrm{~m}$ with $a=7.02 \AA$. (7) Like adamantane this substance is characterized by a relatively high melting point -about $280^{\circ} \mathrm{C}^{(8)}$ because of the molecular symmetry and relatively strong intermolecular forces.

The heat capacities of these substances were determined by precise adiabatic calorimetry and are depicted in Fig. 2. Although the temperature dependence of the heat capacity is similar in general for both substances, the transition in adamantane is pronounced. Apparent heat capacities as high as $4500 \mathrm{cal} /(\mathrm{deg}$ mole) were observed at the peak. Thermal equilibrium was reached within an hour's time in the transition region. The enthalpy of transition of adamantane is $807 \mathrm{cal} / \mathrm{mole}$ and the entropy increment of transition is 3.87 e.u. In some respects these represent minimal values since the interpolated dashed line in Fig. 2 is used to represent the background or lattice heat capacity. Since the transformation is apparently a first order phase transition, separate extrapolations of the heat capacities of both the high and low temperature forms might have been more appropriate and would almost certainly have led to larger values of the increments; the proper extrapolations on this basis are quite ambiguous. A brief summary of the thermodynamic properties of these compounds is given in Table 1. 


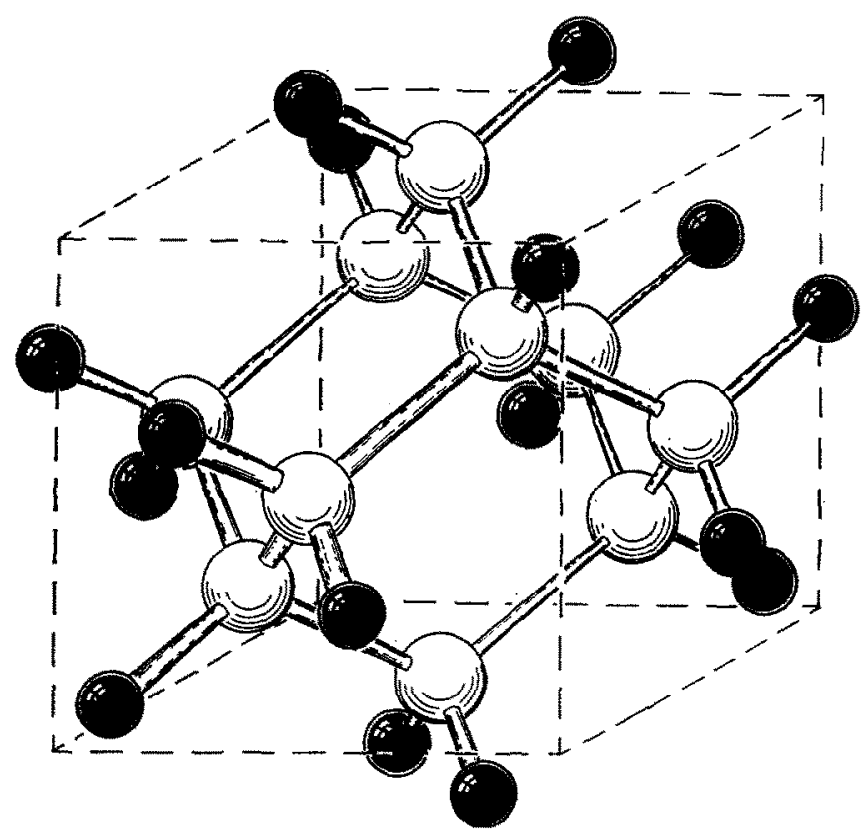

FIG, 1(a)

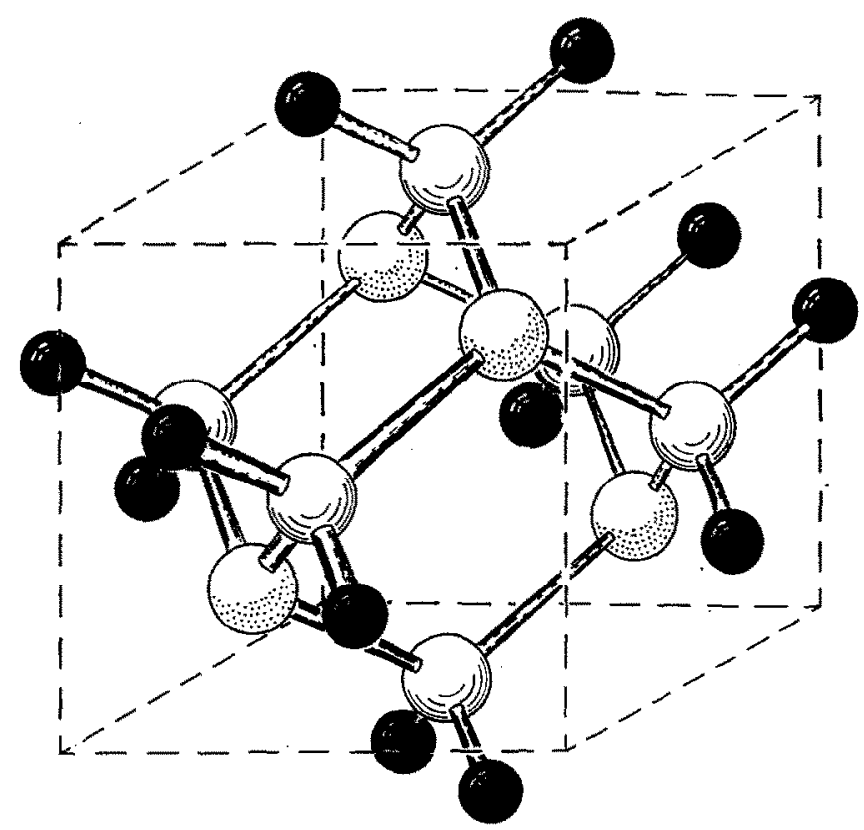

FIG. 1(b)

Fic. 1. The molecular structures of (a) adamantane and (b) hexamethylenetetramine. 
Table 1. Comparison of thermodynamic properties of adamantane $(A)$, hexamethylenetetramine (HMT) and triethylenediamine (TED) at $298.15^{\circ} \mathrm{K}$ in cal/(deg mole)

\begin{tabular}{l|c|c|c|c}
\hline \hline \multicolumn{1}{c|}{ Compound } & $C_{p}$ & $S^{\circ}$ & $\left(H^{\circ}-H_{0}^{\circ}\right) / T$ & $-\left(F^{\circ}-H_{0}^{\circ}\right) / T$ \\
\hline A & $45 \cdot 35$ & 46.80 & $24 \cdot 38$ & $22 \cdot 42$ \\
HMT & 36.42 & 39.05 & 18.26 & $19 \cdot 65$ \\
TED & 36.61 & 37.67 & 18.52 & 19.14 \\
\hline \hline
\end{tabular}

Adamantane is the prototype for a considerable variety of diamondoid derivatives obtained by substituting nitrogen, oxygen, sulfur, and phosphorus into the skeleton. The most readily synthesized of these compounds having suitably

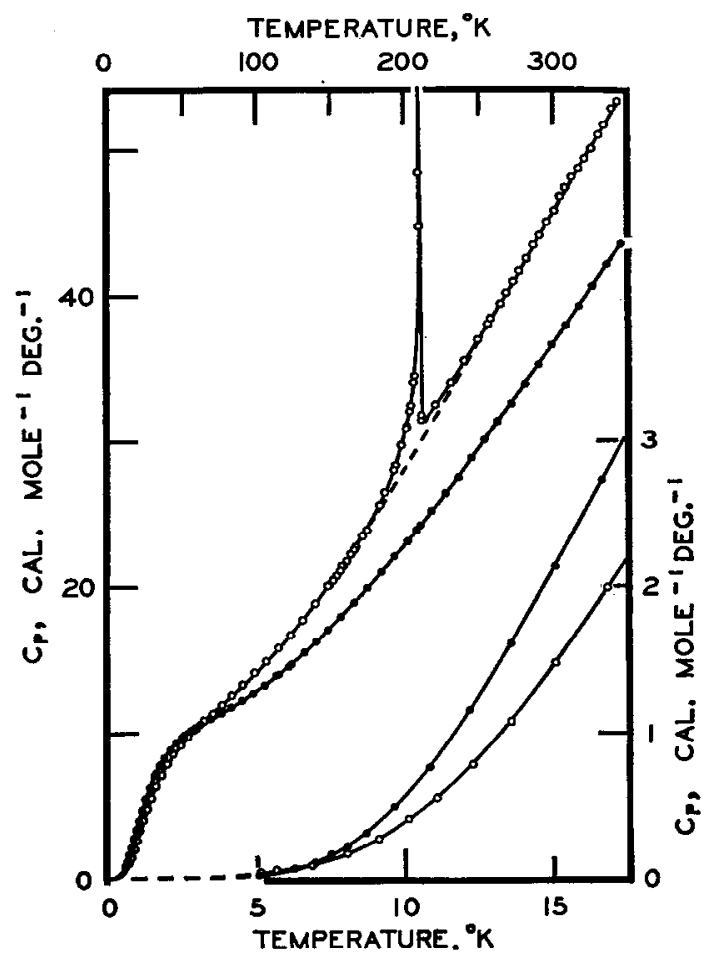

FIc. 2. Molal heat capacities of adamantane $(O)$ and hexamethylenetetramine (0).

tailored symmetries are currently being examined by thermophysical techniques. The higher temperature heat capacities, energetics of pseudorotation and fusion transitions are also under study,

\section{TRIETHYLENEDIAMINE*}

This globular molecule possesses the shape of a symmetrical top rather than the sphericity characteristic of the diamondoid compounds. Triethylenediamine undergoes transition from a $C_{6, d}^{2}-P 6_{3 / m}$ space lattice ${ }^{(9)}$ to a presumably more symmetrical structure at about $353^{\circ} \mathrm{K}$, rather than at the temperature of $74^{\circ} \mathrm{C}\left(347^{\circ} \mathrm{K}\right)$ reported by FARKAS et $a l .{ }^{(10)}$ No anomalies are found in the heat capacity from 5 to $350^{\circ} \mathrm{K}$. Thermodynamic functions of triethylenediamine are included in Table 1 . The thermodynamics of the $353^{\circ} \mathrm{K}$ and fusion transitions are under investigation.

This work is being done with the collaboration of SHU-SING Chang and is partially supported by the Division of Research of the U.S. Atomic Energy Commission.

* $\mathrm{C}_{6} \mathrm{~N}_{2} \mathrm{H}_{12}, 1,4$-diazabicyclo[2, 2, 2]octane.

\section{REFERENCES}

1. Timmermans J., Bull. Soc. Chim. Belg. 44, 17 (1935); Industr. Chim. Belge 16, 178 (1951).

2. NowackI W., Helv. Chim. Acta 28, 1233 (1945).

3. Landa S., Kriebel S. and KNobloch E., Chem. Listy 48, 161 (1954).

4. Chang S. S. and Westrum E. F., Jr., J. Phys. Chem. 64, 1547 (1960).

5. Nordman C. E., unpublished data.

6. Schleyer P. V. R., J. Amer. Chem. Soc. 79, 3292 (1957).

7. Dickinson R. G. and Raymond A. L., $J$. Amer. Chem. Soc. 45, 22 (1923); Gonell H. W. and Mark H., Z. Phys. Chem. 107, 181 (1923); MARK H., Ber. 57B, 1820 (1923); Wyckofr R. W. G. and CoREY R. B., Z. Kristall. 89, 462 (1934); Brill R., Grimm G. H., Hermann C. and Petzrs C., Ann. Phys. Lpz. 34, 383 (1939); Shaffer P. A., Jr., J. Amer. Chem. Soc. 69, 1557 (1947).

8. Grassi G., Gazz. Chim. Ital. 36II, 505 (1906).

9. SkKI S., unpublished data.

10. Farkas A., Mills G. A., ERnkr W. E. and Makruker J. B., Industr. Engng. Chem. 51, 1299 (1959); J. Chem. Eng. Data 4, 334 (1959). 